\title{
Comment on Boka et al.: Dental caries and oral health-related factors in a sample of Greek preschool children
}

\author{
Markku Larmas
}

Received: 22 January 2014 / Accepted: 5 February 2014/Published online: 26 February 2014

(C) European Academy of Paediatric Dentistry 2014

\section{Dear Editor,}

Boka et al. (2013) state in their Abstract: "The caries prevalence was $22.6 \%$. This statement is incorrect, because it is based on the observation reported in the Results section: "77.4\% of children were caries-free". In fact that correct figure (77.4\%) is the prevalence of cariesfree state, which does not mean that the rest of the population has "present caries".

"Past caries" may represent restorations, when carious tissue is removed and replaced by filling, or else extracted teeth because of caries. The F (f) or M (m) components of the DMF (dmf) index never represent present caries because past and present never meet (Larmas 2010).

Oral epidemiology is based on the use of certain index values. A search for the term "caries prevalence" reveals 11,196 entries in PubMed (10.1.2014). The real prevalence is completely unknown, as we recently reported (Larmas and Mäkinen 2014).

I believe that dental caries and periodontitis are among the most widespread chronic, infectious, non-communicable diseases among humans and I am dismayed that these diseases have remained as the only two ailments without scientific knowledge of their real prevalence.

A reply to this comment can be found at doi:10.1007/s40368-0140125-0

M. Larmas $(\bowtie)$

Institute of Dentistry, University of Oulu, Oulu, Finland

e-mail: markku.larmas@oulu.fi

\section{References}

Boka V, Trikaliotis A, Kotsanos N, Karagiannis V. Dental caries and oral health-related factors in a sample of Greek preschool children. Eur Arch Paediatr Dent. 2013;14:363-8. doi:10.1007/ s40368-013-0097-5.

Larmas M. Has dental caries prevalence some connection with caries index values in adults? Caries Res. 2010;44(1):81-4.

Larmas M, Mäkinen KK. Insufficiency of currently used dental indices in epidemiology. Br J Med Med Res. 2014;4(10):2058-64. 